\title{
Associations between blood cadmium and endocrine features related to PCOS- phenotypes in healthy women of reproductive age: a prospective cohort study
}

Keewan Kim', Anna Z. Pollack², Carrie J. Nobles', Lindsey A. Sjaarda', Jessica R. Zolton ${ }^{1,3}$, Jeannie G. Radoc ${ }^{1}$, Enrique F. Schisterman ${ }^{1}$ and Sunni L. Mumford ${ }^{1 *}$ (D)

\begin{abstract}
Background: Cadmium is an endocrine disrupting chemical that affects the hypothalamic-pituitary-gonadal axis. Though evidence suggests its potential role in altering androgen synthesis and metabolic pathways that are characteristic of polycystic ovary syndrome (PCOS), its relation in healthy women of reproductive age is largely unknown. As women with mild sub-clinical features of PCOS who do not meet the diagnostic criteria of PCOS may still experience reduced fecundability, investigating associations between cadmium and PCOS-phenotypes among healthy women may provide unique insight into the reproductive implications for many on the PCOS spectrum. Therefore, the objective of this study was to evaluate associations between cadmium and androgens, anti-Müllerian hormone (AMH), and metabolic markers in women of reproductive age.

Methods: This was a prospective cohort study of 251 healthy premenopausal women without self-reported PCOS (mean age 27.3 years and BMI $24.1 \mathrm{~kg} / \mathrm{m}^{2}$ ). Cadmium was measured in blood collected at baseline. Reproductive hormones and metabolic markers were measured in fasting serum 8 times per menstrual cycle for 2 cycles. Linear mixed models and Poisson regression with a robust error variance were used to examine associations between cadmium and reproductive hormones and metabolic markers and anovulation, respectively.
\end{abstract}

\footnotetext{
* Correspondence: mumfords@mail.nih.gov

'Epidemiology Branch, Division of Intramural Population Health Research, Eunice Kennedy Shriver National Institute of Child Health and Human

Development, 6710B Rockledge Drive MSC 7004, Maryland 20892 Bethesda USA

Full list of author information is available at the end of the article
}

(c) The Author(s). 2021 Open Access This article is licensed under a Creative Commons Attribution 4.0 International License, which permits use, sharing, adaptation, distribution and reproduction in any medium or format, as long as you give appropriate credit to the original author(s) and the source, provide a link to the Creative Commons licence, and indicate if changes were made. The images or other third party material in this article are included in the article's Creative Commons licence, unless indicated otherwise in a credit line to the material. If material is not included in the article's Creative Commons licence and your intended use is not permitted by statutory regulation or exceeds the permitted use, you will need to obtain permission directly from the copyright holder. To view a copy of this licence, visit http://creativecommons.org/licenses/by/4.0/. The Creative Commons Public Domain Dedication waiver (http://creativecommons.org/publicdomain/zero/1.0/) applies to the data made available in this article, unless otherwise stated in a credit line to the data. 
Results: Median (interquartile range) blood cadmium concentrations at baseline were 0.30 (0.19-0.43) $\mu \mathrm{g} / \mathrm{L}$. Higher levels of testosterone $(2.2 \%, 95 \%$ confidence interval [CI] 0.4, 4.1), sex hormone-binding globulin $(2.9 \%, 95 \% \mathrm{Cl} 0.5,5.5)$, and $\mathrm{AMH}(7.7 \%, 95 \% \mathrm{Cl} 1.1,14.9)$ were observed per $0.1 \mathrm{\mu g} / \mathrm{L}$ increase in cadmium concentrations. An $18 \%$ higher probability of a mild PCOS-phenotype $(95 \% \mathrm{Cl} 1.06,1.31)$, defined by a menstrual cycle being in the highest quartile of cycle-averaged testosterone and AMH levels, was also found per $0.1 \mathrm{\mu g} / \mathrm{L}$ increase in cadmium levels. No associations were observed for insulin and glucose. These findings were consistent even after analyses were restricted to non-smokers or further adjusted for dietary factors to account for potential sources of exposure.

Conclusions: Overall, among healthy reproductive-aged women, cadmium was associated with endocrine features central to PCOS, but not with metabolic markers. These suggest its potential role in the hormonal milieu associated with PCOS even at low levels of exposure.

Keywords: Cadmium, Testosterone, Anti-Müllerian hormone (AMH), Sex hormone-binding globulin (SHBG), Polycystic ovary syndrome (PCOS)

\section{Background}

Cadmium is a non-essential toxic metal that is ubiquitously found in the environment and does not have a beneficial role in human health. Inhalation of cigarette smoke is one of the major sources of exposure to cadmium, whereas consumption of contaminated foods, such as shellfish, rice, grains, and vegetables, is the main source of exposure among non-smokers [1]. It is an endocrine disrupting chemical that exerts estrogenic effects and has been shown to affect the hypothalamicpituitary-gonadal (HPG) axis [2], which could result in reproductive dysfunction [3]. Toxicity of cadmium that influences reproductive hormones was also evident in our prior study among healthy women of reproductive age with low levels of cadmium exposure. Specifically, blood cadmium concentrations were associated with higher levels of estradiol [4] and lower levels of folliclestimulating hormone (FSH) though did not affect anovulation [5], suggesting that cadmium may affect tightly regulated reproductive hormone levels even at low levels of exposure.

Cadmium was previously hypothesized to have a role in influencing androgens and metabolic features. In experimental studies, exposure to high levels of cadmium has been shown to influence gonadotropic hormone secretion [6,7], induce alterations in androgen biosynthesis [8], and block binding of androgens to the receptor in human prostate cancer cells [9]. Cadmium has been further shown to induce apoptosis in pancreatic beta-cells in mice [10] and hyperglycemia in rats [11], suggesting its potential effect on metabolism.

Though evidence supports an influence of cadmium on androgens and metabolic features, factors commonly associated with polycystic ovary syndrome (PCOS), less is known about the impacts of exposures among healthy reproductive-aged women. Links between PCOSphenotypes in otherwise healthy women and manifestation of overt PCOS are not always clear. However, women with a mild PCOS-phenotype who do not meet the diagnostic criteria of PCOS have still been shown to experience reduced fecundability [12]. As such, investigating associations between cadmium exposure and PCOS-phenotypes among healthy women may provide unique insight into the reproductive implications for many on the PCOS spectrum. Moreover, given that smoking is one of the primary sources of exposure to cadmium associated with significant reproductive harm, it is critical to assess the role of cadmium among non-smoking populations. Therefore, the objective of this study was to evaluate associations between blood cadmium concentrations and androgens, anti-Müllerian hormone $(\mathrm{AMH})$, and metabolic markers in healthy women of reproductive age with low levels of cadmium exposure, primarily non-smokers.

\section{Materials and methods}

\section{Study design and sample collection}

This was a prospective cohort study of healthy regularly menstruating women enrolled in the BioCycle Study which was conducted in western New York in 20052007. The study design was previously described in detail [13]. In brief, women 18-44 years of age with selfreported menstrual cycle lengths of 21-35 days for at least 6 months prior to recruitment and self-reported body mass index (BMI) of $>18$ or $<35 \mathrm{~kg} / \mathrm{m}^{2}$ at screening were eligible for the study. Women who used hormonal contraceptives in the past 3 months prior to screening, were pregnant or breastfeeding in the past 6 months, had a history of ovulatory disorders (e.g., diagnosis of PCOS) or endocrine dysfunction were excluded.

Fasting blood specimens were obtained from each participant up to 8 times per cycle during participant's visits at specific phases of the menstrual cycle, including the second day of menstruation (1 visit), the mid follicular phase ( 1 visit), the periovulatory phase (3 visits), and 
during the early, mid-, and late luteal phase (3 visits). Fertility monitors (Clearblue Easy Fertility Monitor; Inverness Medical, Waltham, MA) and personal cycle length histories were used to determine the timing of visits [14]. Overall, data for 2 cycles from 250 women and 1 cycle from 9 women were collected, with $94 \%$ of the participants completing at least 7 clinic visits per cycle. The University at Buffalo Health Sciences Institutional Review Board (IRB) served as the IRB designated by the National Institutes of Health under a reliance agreement and approved the study. All study participants provided written informed consent.

\section{Blood cadmium analysis}

At the screening visit, whole blood was collected in purple-top Vacutainer tubes (Becton, Dickinson and Company, Franklin Lakes, NJ) that contained ethylendiaminetetraacetic acid (EDTA). Cadmium concentrations were determined in 252 out of 259 women enrolled in the study using inductively coupled plasma mass spectrometry at the Division of Laboratory Sciences of the National Center for Environmental Health at the Centers for Disease Control and Prevention (Atlanta, GA). Approximately $25 \%$ of the samples were below the limit of detection $(0.20 \mu \mathrm{g} / \mathrm{dL})$ and machine read values were not substituted to minimize potential bias [15]. The interassay coefficient of variation $(\mathrm{CV})$ was $4.3 \%$ at $2.04 \mu \mathrm{g} / \mathrm{dL}$. One individual had cadmium concentrations greater than 3 standard deviations (SDs) from the mean of the overall sample and was therefore excluded from this analysis; the final sample included 251 women.

\section{Measurement of reproductive hormones and metabolic markers}

Total testosterone (ng/dL) was measured in serum samples by a liquid chromatography/tandem mass spectrometry using a Shimadzu Prominence Liquid Chromatograph (Shimadzu Scientific Instruments, Inc., Columbia, MD) with an ABSceix 5500 tandem mass spectrometer (AB SCIEX, Framingham, MA) at the University of Minnesota, Minneapolis, MN. Increased sensitivity was obtained using Mobile Phase B (100\% acetonitrile) with a low standard of $4 \mathrm{ng} / \mathrm{dL}$ added to the standard curve. Serum AMH $(\mathrm{ng} / \mathrm{mL})$ was measured using the GEN II ELISA assay (Beckman Coulter, Inc, Brea, CA). Concentrations of sex hormone-binding globulin (SHBG, nmol/L) were determined using solidphase competitive chemiluminescent enzymatic immunoassays (Specialty Laboratories Inc., Valencia, CA) on a DPC Immulite 2000 analyzer (Siemens Medical Solutions Diagnostics, Deerfield, IL) at the Kaleida Health Center for Laboratory Medicine, Buffalo, NY [13]. The CVs were $<7 \%$ for total testosterone, $<12 \%$ for $\mathrm{AMH}$, and $<10 \%$ for SHBG. Free testosterone was calculated as $24.00314 \times$ (total testosterone $/ \log _{10} \mathrm{SHBG}$ ) $-0.0499 \times$ (total testosterone $)^{2}$ [16] and free androgen index as $100 \times$ (total testosterone/SHBG), based on standardized methods described previously [17].

Metabolic markers were determined in serum and plasma samples. Insulin $(\mu \mathrm{U} / \mathrm{mL})$ was measured in serum using a competitive chemiluminescent enzymatic immunoassay and glucose $(\mathrm{mg} / \mathrm{dL})$ was determined in plasma using a hexokinase-based method on a Beckman LX20 autoanalyzer (Beckman Coulter, Inc, Brea, CA). The CVs were $<8 \%$ for insulin and $<3 \%$ for glucose. Homeostatic Model Assessment of Insulin Resistance (HOMA-IR), a marker of insulin resistance, was calculated as (fasting insulin $\times$ fasting glucose)/22.5, and described elsewhere [18].

\section{Covariate assessment}

At baseline, participants completed questionnaires on demographic characteristics (e.g., race, education), lifestyle factors (e.g., cigarette smoking, physical activity, diet), and reproductive history (e.g., past oral contraceptive use, parity). Physical activity was assessed using the International Physical Activity Questionnaire (IPAQ) long form 2002 [19], and the level of physical activity was estimated as high, moderate, and low based on standard IPAQ cutoffs. Dietary factors were assessed using a food frequency questionnaire which captured food intakes during the previous 6 months (Fred Hutchinson Cancer Center, Seattle, WA). Weight and height of participants were measured by trained staff according to standardized protocols to calculate BMI $\left(\mathrm{kg} / \mathrm{m}^{2}\right)$.

\section{Statistical analysis}

Demographic and lifestyle factors (mean \pm SD or $\mathrm{n}[\%]$ ) were compared by tertile of blood cadmium levels, using Fisher's exact tests and ANOVAs. Cadmium concentrations were rescaled for regression analyses given low levels of exposure in participants. Associations between blood cadmium concentrations (per $0.1 \mu \mathrm{g} / \mathrm{L}$ increase) and log-transformed reproductive hormones and metabolic markers were evaluated using linear mixed models, accounting for repeated measures within woman during the cycle and across cycles. Models were adjusted for age (years), BMI $\left(\mathrm{kg} / \mathrm{m}^{2}\right)$, race (white, black, or other), and parity (nulliparous vs. parous) (Model 1). Results were compared with models that additionally adjusted for smoking status (current vs. no or former smokers) (Model 2). In a separate analysis, models were further adjusted for consumption of either rice, grains, and leafy vegetables in order to investigate the potential impact of dietary factors that might be related to cadmium exposure and PCOS $[1,20]$. Results were presented as percent differences and $95 \%$ confidence intervals (CIs). All analyses were repeated only among non-smokers. 
Associations between blood cadmium concentrations and a mild PCOS-phenotype were further examined by considering both total testosterone and AMH. Specifically, using cycle-averaged levels of total testosterone and $\mathrm{AMH}$, cycles were categorized into a mild PCOSphenotype (i.e., both testosterone and AMH being in the upper 75th percentile) versus no (i.e., either or both testosterone and $\mathrm{AMH}$ in the lower 75th percentile). Poisson regression with a robust error variance was used to estimate risk ratios (RRs) and $95 \%$ CIs. Models were adjusted for the same covariates listed above. SAS version 9.4 (SAS Institute, Cary, NC) was used for all statistical analyses.

\section{Results}

Median (interquartile range; IQR) levels of blood cadmium were $0.30(0.19-0.43) \mu \mathrm{g} / \mathrm{L}$ in 251 participants (Table 1). Women in the highest tertile of blood cadmium concentrations tended to be older (mean $\pm \mathrm{SD}$; highest tertile $29.9 \pm 8.2$ years of age, lowest tertile $25.7 \pm 7.8$ ) and self-identified as black or other than white or black for race/ethnicity. $4 \%$ of women were current smokers and smoking status was positively correlated with blood cadmium concentrations $(P=0.01)$. No other demographic or lifestyle characteristics were correlated with blood cadmium levels.

Positive associations between blood cadmium concentrations and reproductive hormones that are characteristic of PCOS were observed (Table 2). Specifically, a $0.1 \mu \mathrm{g} / \mathrm{L}$ increase in blood cadmium concentrations was associated with $2.2 \%$ higher total testosterone (95\% CI 0.4, 4.1), $2.9 \%$ higher SHBG (95\% CI 0.5, 5.5), and $7.7 \%$ higher $\mathrm{AMH}$ (95\% CI 1.1, 14.9), adjusting for age, BMI, race, parity, and cigarette smoking (Model 2). Unlike hormones, no associations were indicated for blood cadmium with metabolic markers, including insulin, glucose, and HOMA-IR. No appreciable changes were found after further adjusting for dietary factors that might be related to cadmium exposure and PCOS, including consumption of rice, grains, and green vegetables (Table 3). Our results were also consistent after analyses were restricted to nonsmokers (Supplementary Table 1).

Among 480 cycles from women who had both total testosterone and AMH measurements, 56 (11.7\%) were classified as a mild PCOS-phenotype, defined by a cycle being in the highest quartile of total testosterone and AMH (Table 4). Of remaining cycles, 64 cycles were in the lower 75 th percentile of testosterone, 56 cycles were in the lower 75th percentile of $\mathrm{AMH}$, and 304 cycles were in the lower 75th percentile for both testosterone and $\mathrm{AMH}$. Our data suggested that each $0.1 \mu \mathrm{g} / \mathrm{L}$ increase in blood cadmium levels was associated with an $18 \%$ higher probability of a mild PCOS-phenotype (RR 1.18; $95 \%$ CI 1.06, 1.31; Model 2).

\section{Discussion}

Among healthy premenopausal women without a diagnosis of PCOS, higher blood cadmium concentrations were associated with elevated testosterone and $\mathrm{AMH}$

Table 1 Demographic and lifestyle characteristics by blood cadmium concentrations in 251 participants in the analysis

\begin{tabular}{|c|c|c|c|c|c|}
\hline Mean \pm SD or $n(\%)$ & Overall & Tertile 1 & Tertile 2 & Tertile 3 & $P$-value \\
\hline $\mathrm{N}$ & 251 & 82 & 88 & 81 & \\
\hline Blood cadmium ( $\mu \mathrm{g} / \mathrm{L} ;$ median [IQR]) & $0.30(0.19-0.43)$ & $0.15(0.12-0.19)$ & $0.30(0.26-0.33)$ & $0.50(0.44-0.68)$ & \\
\hline \multicolumn{6}{|l|}{ Demographic factors } \\
\hline Age, year & $27.3 \pm 8.2$ & $25.7 \pm 7.8$ & $26.4 \pm 7.5$ & $29.9 \pm 8.2$ & 0.002 \\
\hline $\mathrm{BMl}, \mathrm{kg} / \mathrm{m}^{2}$ & $24.1 \pm 3.8$ & $24.1 \pm 3.8$ & $24.1 \pm 3.9$ & $24.0 \pm 3.8$ & 0.984 \\
\hline Race & & & & & 0.001 \\
\hline White & $149(59)$ & $61(74)$ & $50(57)$ & $38(47)$ & \\
\hline Black & $51(20)$ & $15(18)$ & $19(22)$ & $17(21)$ & \\
\hline Other & $51(20)$ & $6(7)$ & $19(22)$ & $26(32)$ & \\
\hline High school education or less & $31(12)$ & $9(11)$ & $11(13)$ & $11(14)$ & 0.862 \\
\hline \multicolumn{6}{|l|}{ Lifestyle factors } \\
\hline Physical activity & & & & & 0.088 \\
\hline High & $139(55)$ & $11(13)$ & $5(6)$ & $8(10)$ & \\
\hline Moderate & $88(35)$ & $21(26)$ & $32(36)$ & $35(43)$ & \\
\hline Low & $24(10)$ & $50(61)$ & $51(58)$ & $38(47)$ & \\
\hline Current smoking & $10(4)$ & $0(0)$ & $3(3)$ & $7(9)$ & 0.011 \\
\hline Parous & $65(26)$ & $18(23)$ & $23(27)$ & $24(30)$ & 0.823 \\
\hline Oral contraceptive use & $136(55)$ & $44(54)$ & $50(57)$ & $42(53)$ & 0.959 \\
\hline
\end{tabular}

$B M I$ body mass index, $I Q R$ interquartile range, $S D$ standard deviation 
Table 2 Associations between blood cadmium concentrations (per $0.1 \mu \mathrm{g} / \mathrm{L}$ ) and reproductive hormones and metabolic markers

\begin{tabular}{|c|c|c|c|}
\hline & Unadjusted & Model 1 & Model 2 \\
\hline & \%Difference $(95 \% \mathrm{Cl})$ & \%Difference (95\% Cl) & \%Difference $(95 \% \mathrm{Cl})$ \\
\hline \multicolumn{4}{|l|}{ Reproductive hormones } \\
\hline Testosterone (ng/dL) & $0.5(-1.3,2.3)$ & $2.0(0.3,3.7)^{*}$ & $2.2(0.4,4.1)^{*}$ \\
\hline Free testosterone $(\mathrm{ng} / \mathrm{dL})$ & $-0.4(-2.2,1.3)$ & $1.3(-0.3,2.8)$ & $1.3(-0.3,3.0)$ \\
\hline Free androgen index & $-2.6(-5.0,-0.1)^{*}$ & $-0.3(-2.5,2.0)$ & $-0.8(-3.1,1.6)$ \\
\hline SHBG (nmol/L) & $3.2(0.8,5.7)^{* *}$ & $2.2(-0.1,4.5)$ & $2.9(0.5,5.5)^{*}$ \\
\hline $\mathrm{AMH}(\mathrm{ng} / \mathrm{mL})$ & $-2.0(-8.5,5.0)$ & $5.9(-0.3,12.4)$ & $7.7(1.1,14.9)^{*}$ \\
\hline \multicolumn{4}{|l|}{ Metabolic markers } \\
\hline Insulin $(\mu \mathrm{U} / \mathrm{mL})$ & $-2.1(-4.0,-0.1)^{*}$ & $-1.6(-3.4,0.2)$ & $-1.3(-3.2,0.6)$ \\
\hline Glucose (mg/dL) & $0.1(-0.2,0.4)$ & $0.0(-0.3,0.3)$ & $0.1(-0.3,0.4)$ \\
\hline HOMA-IR & $-1.9(-4.0,0.1)$ & $-1.6(-3.5,0.3)$ & $-1.2(-3.3,0.8)$ \\
\hline
\end{tabular}

Model 1: Adjusted for age, BMI, race, and parity

Model 2: Adjusted for age, BMI, race, parity, and smoking

${ }^{*} P<0.05,{ }^{* *} P<0.01$

$A M H$ anti Müllerian hormone, BMI body mass index, $C l$ confidence interval, HOMA-IR homeostatic model assessment of insulin resistance, SHBG sex hormone-binding globulin

levels, key endocrine markers that are central to PCOS. Our data also supported that increasing blood cadmium concentrations were associated with higher concentrations of SHBG. In contrast, no associations were observed between cadmium and metabolic markers, including insulin and glucose. Our findings were consistent among non-smokers or even after adjusting for certain food intakes, including rice, grains, and green vegetables, that are potentially important in the association between cadmium exposure and PCOS-related features. Overall, these findings suggest a potential role of cadmium in the hormonal milieu, but not metabolic pathway, associated with PCOS among healthy women of reproductive age, even at low levels of exposure.
Our findings of increased testosterone levels with higher blood cadmium concentrations are in line with prior studies among postmenopausal women, where high levels of blood [21] and urinary cadmium [22] were associated with elevated serum testosterone concentrations. However, our findings are in contrast to more recent studies, which observed lower concentrations of testosterone with higher levels of blood cadmium (mean $1.90 \mu \mathrm{g} / \mathrm{L})$ in Chinese men [23] and with increasing urinary cadmium in pre- (mean $2.33 \mu \mathrm{g} / \mathrm{L}$ ) and postmenopausal (mean $3.21 \mu \mathrm{g} / \mathrm{L}$ ) Japanese women [24], though levels of cadmium measured in these studies were substantially higher than in our data. Cadmium may exert reproductive toxicity via influences on the

Table 3 Associations between blood cadmium concentrations (per $0.1 \mu \mathrm{g} / \mathrm{L}$ ) and reproductive hormones and metabolic markers, adjusting for dietary factors

\begin{tabular}{|c|c|c|c|}
\hline & $\begin{array}{l}\text { Adjusted for rice } \\
\text { \%Difference }(95 \% \mathrm{Cl})\end{array}$ & $\begin{array}{l}\text { Adjusted for grains } \\
\text { \%Difference }(95 \% \mathrm{Cl})\end{array}$ & $\begin{array}{l}\text { Adjusted for green vegetables } \\
\text { \%Difference }(95 \% \mathrm{Cl})\end{array}$ \\
\hline \multicolumn{4}{|c|}{ Reproductive hormones } \\
\hline Testosterone & $2.2(0.4,4.1)^{*}$ & $2.2(0.4,4.1)^{*}$ & $2.2(0.4,4.1)^{*}$ \\
\hline Free testosterone & $1.3(-0.4,3.0)$ & $1.3(-0.4,3.0)$ & $1.3(-0.4,3.0)$ \\
\hline Free androgen index & $-0.7(-3.0,1.7)$ & $-0.8(-3.2,1.6)$ & $-0.8(-3.1,1.6)$ \\
\hline SHBG & $2.9(0.4,5.4)^{*}$ & $3.0(0.6,5.6)^{*}$ & $3.0(0.5,5.5)^{*}$ \\
\hline AMH & $6.1(-0.5,13.1)$ & $7.6(0.9,14.8)^{*}$ & $7.6(0.9,14.7)^{*}$ \\
\hline \multicolumn{4}{|l|}{ Metabolic markers } \\
\hline Insulin & $-1.3(-3.2,0.7)$ & $-1.3(-3.2,0.6)$ & $-1.3(-3.2,0.6)$ \\
\hline Glucose & $0.1(-0.2,0.4)$ & $0.1(-0.3,0.4)$ & $0.1(-0.2,0.4)$ \\
\hline HOMA-IR & $-1.2(-3.2,0.9)$ & $-1.2(-3.2,0.8)$ & $-1.2(-3.2,0.8)$ \\
\hline
\end{tabular}

Note: All models were adjusted for age, $\mathrm{BMI}$, race, parity, and smoking. ${ }^{*} P<0.05$

$A M H$ anti Müllerian hormone, $B M I$ body mass index, $C I$ confidence interval, HOMA-IR homeostatic model assessment of insulin resistance, SHBG sex hormone-binding globulin 
Table 4 Associations between blood cadmium concentrations and PCOS-phenotype defined by cycles being in the highest quartile of total testosterone and $\mathrm{AMH}$

\begin{tabular}{ll}
\hline & RR $(\mathbf{9 5} \% \mathbf{C l})$ \\
\hline Unadjusted & $1.05(0.92,1.20)$ \\
Model 1 & $1.16(1.04,1.29)^{* *}$ \\
Model 2 & $1.18(1.06,1.31)^{* *}$ \\
\hline
\end{tabular}

Model 1: Adjusted for age, BMI, race, and parity

Model 2: Adjusted for age, BMI, race, parity, and smoking

${ }^{* *} P<0.01$

$A M H$ anti Müllerian hormone, $B M I$ body mass index, $\mathrm{Cl}$ confidence interval, $P C O S$ polycystic ovary syndrome, $R R$ risk ratio

HPG-axis, particularly through effects on the pituitary gland, altering gonadotropin pulsatility and thereby influencing the release of gonadotropic hormones, and subsequently altering testosterone levels [3]. Indeed, we previously observed a decrease in FSH with increasing blood cadmium levels in this cohort [5], further supporting this mechanism. Alternatively, our findings could be in part explained by the effect of cadmium on the androgen receptors at the ovary. Androgen-like activity of cadmium has been suggested in experimental studies where cadmium was shown to trigger an androgenspecific reporter gene in human prostate epithelial cells in the presence of the androgen receptor [25] and block the binding of androgens to the receptor in human prostate cancer cells [9]. Thus, it is plausible that cadmium may share biological activity with androgens, bind to androgen receptors at ovary, and stimulate testosterone production as observed in our data.

A positive association between cadmium and SHBG was indicated in our data and this was expected as increases in sex steroids are linked to increases in SHBG. Alternatively, the observed association may be related to cadmium's ability to bind to SHBG. Specifically, cations (e.g., $\mathrm{Ca}^{2+}, \mathrm{Zn}^{2+}$ ) including cadmium are able to bind to SHBG, competing with estradiol and androgens [26], and this in turn can stimulate SHBG production in the liver [27]. This potential mechanism is in line with our observation for testosterone as well, since binding of cadmium to SHBG may interfere with binding of testosterone to SHBG which subsequently can lead to small increases in testosterone levels in circulation. Increased SHBG levels were also observed in men at slightly higher levels of blood cadmium (median $0.38 \mu \mathrm{g} / \mathrm{L}$, 10th -90 th percentile $0.05-1.27$ [28] or weighted median $0.40 \mu \mathrm{g} / \mathrm{L}$, IQR $0.20-0.70$ [29]) than in our cohort (median 0.30, IQR 0.19-0.43). Though cadmium levels measured in the general population $[28,29]$ as well as in our cohort are much lower than in the prior experimental studies [26], taken together this evidence may point to the potential contribution of cadmium on influencing SHBG.

$\mathrm{AMH}$ is produced in the granulosa cells of the small preantral and antral follicles and is relatively higher among women with PCOS [30]. Our finding is consistent with the result from a cross-sectional study among pregnant women, where a positive relationship was suggested for blood cadmium and AMH levels [31]. However, our result differs from a recent study among premenopausal women, which reported an inverse association between blood cadmium and AMH concentrations, though mean age of participants in that study were higher than ours (mean \pm SD, $36.2 \pm 3.9$ vs. $27.3 \pm 8.2$ ) [32]. Specific mechanisms are unclear; however, our observation of an increase in AMH with higher cadmium concentrations could be related to the effect through damage of granulosa cells [33] or alterations in the blood-follicle-barrier due to cadmium toxicity, as disruption of the follicle membrane integrity may potentially lead to an increase in the release of $\mathrm{AMH}$ from the follicles $[34,35]$.

High levels of cadmium have induced hyperglycemia [11] and apoptosis in pancreatic beta-cells in rats and mice [10], suggesting a potential role in metabolic dysregulation. However, despite the well-established toxicological effects of cadmium on metabolic function in animal studies, epidemiological evidence is inconsistent perhaps due to differences in population, levels of exposure, and lifestyle factors that affect the body burden of cadmium. In a cross-sectional study using a large sample from the National Health And Nutrition Examination Survey (NHANES) 1988-1994 ( $\geq 40$ years old), urinary cadmium (mean 0.92 and $0.63 \mu \mathrm{g} / \mathrm{g}$ creatinine among smokers and non-smokers, respectively) was associated with impaired fasting glucose and elevated risk of diabetes [36]. On the other hand, a study among older women $(\geq$ 64 years old) with comparable cadmium concentrations to ours (median $0.34 \mu \mathrm{g} / \mathrm{L}$ for blood cadmium and $0.36 \mu \mathrm{g} / \mathrm{g}$ creatinine for urine cadmium) found no associations with insulin sensitivity and glucose tolerance [37]. A more recent study using data from the NHANES 2001-2014 also reported no associations between urinary cadmium and risk of metabolic syndrome in women ( $\geq 20$ years) [38], consist with our null findings. Though metabolic dysregulation is a frequently observed feature among women with PCOS $[39,40]$, our data suggest a minimal effect of low levels of cadmium exposure in relation with changes in metabolic markers in healthy women.

In cross-sectional studies which compared serum cadmium concentrations between women with and without PCOS, no differences in cadmium levels were observed $[41,42]$. In our study where approximately $12 \%$ of the total cycles were classified as a mild PCOS-phenotype using testosterone and $\mathrm{AMH}$ measurements, our data showed that higher cadmium concentrations were associated with a higher probability of a mild PCOSphenotype. It is important to note that even though our findings suggest that cadmium exposure may contribute to alterations in key hormonal characteristics of PCOS, 
it does not imply direct associations with PCOS as our women have never been diagnosed with PCOS and other factors may play a more critical role in leading to manifestation of overt PCOS.

Several strengths and limitations in our study are noteworthy. Cadmium was determined in a single blood sample collected at baseline. Unlike urinary cadmium which reflects long-term exposure, blood cadmium is a marker of a short-term exposure and thus there is a possibility that an already altered hormonal milieu or metabolic function could have affected cadmium metabolism. However, multiple prospective measurements of serum reproductive hormones and metabolic markers across the menstrual cycle may make this case less likely. Blood cadmium measured in our study was lower than in other studies $[36,37]$ possibly due to a small proportion of current smokers in our data $(4 \%)$ which further enables us to distinguish between the deleterious effects of smoking and cadmium exposure. Nevertheless, blood cadmium levels in our study were comparable to that measured among women in NHANES 2005-2006 (geometric mean $0.33,95 \%$ CI $0.31,0.35$ ) [43] or non-smoking women aged 20-44 years in NHANES 2003-2006 (geometric mean $0.34,95 \%$ CI $0.32,0.36$ ) [44]. Importantly, the potential impact of dietary factors that might be related to cadmium exposure and PCOS $[1,20]$ have been accounted during the analysis and consistent results were observed, supporting robustness of our findings between cadmium exposure and PCOS-related endocrine and metabolic features.

\section{Conclusions}

Overall, our findings suggest a potential association between increasing levels of cadmium with higher testosterone, AMH, and SHBG concentrations among healthy women of reproductive age, largely non-smokers with low levels of cadmium exposure. Given the known link between these hormonal factors and PCOS, the most common endocrine disorder in women [45], our findings are important in understanding potential factors that affect the continuum of PCOS. As women with mild sub-clinical features of PCOS may suffer from ovulatory insufficiency and other factors related to impaired fecundability [12], our findings also highlight the need to mitigate exposure to this ubiquitous environmental contaminant through modifiable lifestyle changes for women's reproductive health.

\footnotetext{
Abbreviations

AMH: Anti-Müllerian hormone; BMl: Body mass index; Cl: Confidence interval; CV: Coefficient of variation; FSH: Follicle-stimulating hormone; HPG axis: Hypothalamic-pituitary-gonadal axis; IPAQ: International Physical Activity Questionnaire; LH: Luteinizing hormone; NHANES: National Health And Nutrition Examination Survey; SHBG: Sex hormone-binding protein; PCOS: Polycystic ovary syndrome; RR: Risk ratio
}

\section{Supplementary Information}

The online version contains supplementary material available at https://doi. org/10.1186/s12940-021-00749-4.

\section{Additional file 1.}

Authors' contributions

KK conceptualized the study, analyzed data, interpreted results, and drafted the original manuscript. AZP contributed to revise the manuscript. CJN contributed to revise the manuscript; ALS contributed to revise the manuscript. JRZ contributed to revise the manuscript. JGR contributed to revise the manuscript. EFS obtained data and revised the manuscript. SLM supervised statistical analysis and revised the manuscript. All authors read and approved the final manuscript.

\section{Funding}

This work was supported by the Intramural Research Program of the Eunice Kennedy Shriver National Institute of Child Health and Human Development, National Institutes of Health (Contract Number: HHSN275200403394C, HHSN2752011000021, and Task 1HHSN27500001). JGR has been funded by the NIH Medical Research Scholars Program, a public-private partnership supported jointly by the $\mathrm{NIH}$ and generous contributions to the Foundation for the NIH from the Doris Duke Charitable Foundation (DDCF Grant \# 2014194), Genentech, Elsevier, and other private donors.

\section{Availability of data and materials}

The datasets used and/or analyzed during the current study are available from the corresponding author on reasonable request. Some of baseline demographic data are publicly available from the NICHD's database (Data And Specimen Hub or DASH) at https://dash.nichd.nih.gov.

\section{Declarations}

\section{Ethics approval and consent to participate}

This study was conducted based on the Code of Ethics of the World Medical Association (Declaration of Helsinki) for experiments involving humans. The University at Buffalo Health Sciences Institutional Review Board (IRB) served as the IRB designated by the National Institutes of Health under a reliance agreement and approved the study

Consent for publication

Not applicable.

\section{Competing interests}

The authors have nothing to disclose.

\section{Author details}

${ }^{1}$ Epidemiology Branch, Division of Intramural Population Health Research, Eunice Kennedy Shriver National Institute of Child Health and Human Development, 6710B Rockledge Drive MSC 7004, Maryland 20892 Bethesda, USA. ${ }^{2}$ George Mason University, 22030 Fairfax, Virginia, USA. ${ }^{3}$ Program in Reproductive Endocrinology and Gynecology, Eunice Kennedy Shriver National Institute of Child Health and Human Development, 20892 Bethesda, Maryland, USA.

Received: 21 September 2020 Accepted: 10 May 2021

Published online: 22 May 2021

\section{References}

1. Agency for Toxic Substances and Disease Registry (ATSDR). Toxicological profile for cadmium. Atlanta: US Department of Health and Human Services Public Health Service Agency for Toxic Substances and Disease Registry; 2012. Available online: https://www.atsdr.cdc.gov/toxprofiles/tp5.pdf.

2. Marshall JC, Eagleson CAMCCartney CR. Hypothalamic dysfunction. Mol Cell Endocrinol. 2001;183(1-2):29-32.

3. Lafuente A. The hypothalamic-pituitary-gonadal axis is target of cadmium toxicity. An update of recent studies and potential therapeutic approaches. Food Chem Toxicol. 2013;59:395-404.

4. Jackson LW, Howards PP, Wactawski-Wende JSchisterman EF. The association between cadmium, lead and mercury blood levels and 
reproductive hormones among healthy, premenopausal women. Hum Reprod. 2011;26(10):2887-95.

5. Pollack AZ, Schisterman EF, Goldman LR, Mumford SL, Albert PS, Jones RL, et al. Cadmium, lead, and mercury in relation to reproductive hormones and anovulation in premenopausal women. Environ Health Perspect. 2011; 119(8):1156-61.

6. Lafuente A, Marquez N, Perez-Lorenzo M, Pazo DEsquifino Al. Pubertal and postpubertal cadmium exposure differentially affects the hypothalamic-pituitarytesticular axis function in the rat. Food Chem Toxicol. 2000;38(10):913-23.

7. Lafuente A, Marquez N, Perez-Lorenzo M, Pazo DEsquifino Al. Cadmium effects on hypothalamic-pituitary-testicular axis in male rats. Exp Biol Med. 2001;226(6):605-11.

8. Sangalang GBO'Halloran MJ. Cadmium-induced testicular injury and alterations of androgen synthesis in brook trout. Nature. 1972;240(5382):470-1.

9. Martin MB, Voeller HJ, Gelmann EP, Lu J, Stoica EG, Hebert EJ, et al. Role of cadmium in the regulation of AR gene expression and activity. Endocrinology. 2002;143(1):263-75.

10. Chang KC, Hsu CC, Liu SH, Su CC, Yen CC, Lee MJ, et al. Cadmium induces apoptosis in pancreatic beta-cells through a mitochondria-dependent pathway: the role of oxidative stress-mediated c-Jun N-terminal kinase activation. PLoS One. 2013;8(2):e54374.

11. Bell RR, Early JL, Nonavinakere VKMallory Z. Effect of cadmium on blood glucose level in the rat. Toxicol Lett. 1990;54(2-3):199-205.

12. Sjaarda LA, Mumford SL, Kuhr DL, Holland TL, Silver RM, Plowden TC, et al. Association of testosterone and antimullerian hormone with time to pregnancy and pregnancy loss in fecund women attempting pregnancy. Fertil Steril. 2018;109(3):540-8.e1.

13. Wactawski-Wende J, Schisterman EF, Hovey KM, Howards PP, Browne RW, Hediger M, et al. BioCycle study: design of the longitudinal study of the oxidative stress and hormone variation during the menstrual cycle. Paediatr Perinat Epidemiol. 2009;23(2):171-84.

14. Howards PP, Schisterman EF, Wactawski-Wende J, Reschke JE, Frazer AAHovey KM. Timing clinic visits to phases of the menstrual cycle by using a fertility monitor: the BioCycle Study. Am J Epidemiol. 2009;169(1):105-12.

15. Schisterman E, Vexler A, Whitcomb BLiu A. The limitations due to exposure detection limits for regression models. Am J Epidemiol. 2006;163(4):374.

16. Sartorius G, Ly LP, Sikaris K, McLachlan RHandelsman DJ. Predictive accuracy and sources of variability in calculated free testosterone estimates. Ann Clin Biochem. 2009;46(Pt 2):137-43.

17. Sjaarda LA, Schisterman EF, Schliep KC, Plowden T, Zarek SM, Yeung E, et al. Dietary carbohydrate intake does not impact insulin resistance or androgens in healthy, eumenorrheic women. J Clin Endocrinol Metab. 2015; 100(8):2979-86.

18. Wallace TM, Levy JCMatthews DR. Use and abuse of HOMA modeling. Diabetes Care. 2004;27(6):1487-95.

19. Craig $C L$, Marshall AL, Sjostrom M, Bauman AE, Booth ML, Ainsworth BE, et al. International physical activity questionnaire: 12-country reliability and validity. Med Sci Sports Exerc. 2003;35(8):1381-95.

20. Douglas C, Norris L, Oster R, Darnell B, Azziz RGower B. Difference in dietary intake between women with polycystic ovary syndrome and healthy controls. Fertil Steril. 2006;86(2):411.

21. Ali I, Engstrom A, Vahter M, Skerfving S, Lundh T, Lidfeldt J, et al. Associations between cadmium exposure and circulating levels of sex hormones in postmenopausal women. Environ Res. 2014;134:265-9.

22. Nagata C, Nagao Y, Shibuya C, Kashiki YShimizu H. Urinary cadmium and serum levels of estrogens and androgens in postmenopausal Japanese women. Cancer Epidemiol Biomarkers Prev. 2005;14(3):705-8.

23. Chen C, Wang N, Nie X, Han B, Li Q, Chen Y, et al. Blood cadmium level associates with lower testosterone and sex hormone-binding globulin in Chinese men: from SPECT-China Study, 2014. Biol Trace Elem Res. 2016;171(1):71-8.

24. Nagata C, Konishi K, Goto Y, Tamura T, Wada K, Hayashi M, et al. Associations of urinary cadmium with circulating sex hormone levels in preand postmenopausal Japanese women. Environ Res. 2016;150:82-7.

25. Ye J, Wang S, Barger M, Castranova VShi X. Activation of androgen response element by cadmium: a potential mechanism for a carcinogenic effect of cadmium in the prostate. J Environ Pathol Toxicol Oncol. 2000;19(3):275-80.

26. Avvakumov GV, Muller YAHammond GL. Steroid-binding specificity of human sex hormone-binding globulin is influenced by occupancy of a zincbinding site. J Biol Chem. 2000;275(34):25920-5.
27. Hammond GL, Hogeveen KN, Visser MCoelingh Bennink HJ. Estetrol does not bind sex hormone binding globulin or increase its production by human HepG2 cells. Climacteric. 2008;11(Suppl 1):41-6.

28. Dhooge W, den Hond E, Koppen G, Bruckers L, Nelen V, van de Mieroop E, et al. Internal exposure to pollutants and sex hormone levels in Flemish male adolescents in a cross-sectional study: associations and dose-response relationships. J Expo Sci Environ Epidemiol. 2011;21(1):106-13.

29. Kresovich JK, Argos MTuryk ME. Associations of lead and cadmium with sex hormones in adult males. Environ Res. 2015;142:25-33.

30. Dewailly D, Andersen CY, Balen A, Broekmans F, Dilaver N, Fanchin R, et al. The physiology and clinical utility of anti-Mullerian hormone in women. Hum Reprod Update. 2014;20(3):370-85.

31. Christensen PS, Bonde JP, Bungum L, Giwercman A, Toft G, Jonsson BA, et al. Environmental cadmium and lead exposure and anti-Mullerian hormone in pregnant women. Reprod Toxicol. 2016;61:114-9.

32. Lee YM, Chung HW, Jeong K, Sung YA, Lee H, Ye S, et al. Association between cadmium and anti-Mullerian hormone in premenopausal women at particular ages. Ann Occup Environ Med. 2018;30:44.

33. Chen N, Luo L, Zhang C, Liu J, Wang W, Li Y, et al. Anti-Mullerian hormone participates in ovarian granulosa cell damage due to cadmium exposure by negatively regulating stem cell factor. Reprod Toxicol. 2020;93:54-60.

34. Hess KA, Chen LLarsen WJ. The ovarian blood follicle barrier is both chargeand size-selective in mice. Biol Reprod. 1998;58(3):705-11.

35. Siu MKCheng CY. The blood-follicle barrier (BFB) in disease and in ovarian function. Adv Exp Med Biol. 2012;763:186-92.

36. Schwartz $G$, yasova Dlvanova A. Urinary cadmium, impaired fasting glucose, and diabetes in the NHANES III. Diabetes Care. 2003;26(2):468.

37. Barregard L, Bergstrom GFagerberg B. Cadmium exposure in relation to insulin production, insulin sensitivity and type 2 diabetes: a cross-sectional and prospective study in women. Environ Res. 2013;121:104-9.

38. Noor N, Zong G, Seely EW, Weisskopf MJames-Todd T. Urinary cadmium concentrations and metabolic syndrome in U.S. adults: The National Health and Nutrition Examination Survey 2001-2014. Environ Int. 2018;121(Pt 1):349-56.

39. Legro R, Castracane VKauffman R. Detecting insulin resistance in polycystic ovary syndrome: purposes and pitfalls. Obstet Gynecol Surv. 2004;59(2):141.

40. Vrbikova J, Cibula D, Dvorakova K, Stanicka S, Sindelka G, Hill M, et al. Insulin sensitivity in women with polycystic ovary syndrome. J Clin Endocrinol Metab. 2004;89(6):2942.

41. Kurdoglu Z, Kurdoglu M, Demir HSahin HG. Serum trace elements and heavy metals in polycystic ovary syndrome. Hum Exp Toxicol. 2012;31(5):452-6.

42. Zheng G, Wang L, Guo Z, Sun L, Wang L, Wang C, et al. Association of serum heavy metals and trace element concentrations with reproductive hormone levels and polycystic ovary syndrome in a Chinese population. Biol Trace Elem Res. 2015:167(1):1-10.

43. Department of Health and Human Services Centers for Disease Control and Prevention. US Center for Disease Control and Prevention. Fourth National Report on Human Exposure to Environmental Chemicals. Atlanta: Department of Health and Human Services Centers for Disease Control and Prevention; 2014. Available online: https://www.cdc.gov/exposurereport/ pdf/fourthreport.pdf.

44. Mijal RSHolzman CB. Blood cadmium levels in women of childbearing age vary by race/ethnicity. Environ Res. 2010;110(5):505-12.

45. Zhang HY, Zhu FF, Xiong J, Shi XBFu SX. Characteristics of different phenotypes of polycystic ovary syndrome based on the Rotterdam criteria in a large-scale Chinese population. BJOG. 2009;116(12):1633-9.

\section{Publisher's Note}

Springer Nature remains neutral with regard to jurisdictional claims in published maps and institutional affiliations. 